\title{
Laboratory scale tests for the assessment of solid explosive blast effects
}

\author{
K. Cheval ${ }^{1}$, O. Loiseau ${ }^{1} \&$ V. Vala ${ }^{2}$ \\ ${ }^{I}$ Institut de Radioprotection et de Sûreté Nucléaire, Fontenay-Aux-Roses, \\ France \\ ${ }^{2}$ Crit Interim Nucléaire, Antony, France
}

\begin{abstract}
The definition of blast loads applying to a complex geometry structure is, nowadays, still a hard task when numerical simulation is used, essentially because of the different scales involved: as a matter of fact, modelling the detonation of a charge and its resulting load on a structure requires one to model the charge itself, the structure and the surrounding air, which rapidly leads to large size models on which parametrical studies become unaffordable. So, on the basis of the Crank-Hopkinson's law, an experimental set-up has been developed to support reduced scale structures as well as reduced scale detonating solid charges. As a final objective, the set-up must be used to produce the entry data for numerical assessments of the structure resistance.

This set-up is composed of a modular table, sensors and targets and has been designed to conduct nondestructive studies. In the context of security, the general aim is to study the effects of detonation shock waves in the vicinity of test installations and to test various shock wave mitigation means that could be implemented for the protection of facilities in sensitive locations. In particular, the set-up offers the possibility of measuring the loading in terms of pressuretime curves, even for very complex situations like multiple reflections, combination and diffraction.

The present paper summarizes the development of the set-up, as well as the first tests performed. The main features of the table, the instrumentation and the pyrotechnics are given. Also, the paper summarizes a first qualification test campaign that was conducted in the year 2006. In this campaign, free field blast tests (i.e. blast tests performed without structures) have been conducted. Overpressure maxima, arrival time of the shock wave and impulse are presented as nondimensional characteristics of the pressure time history. The results obtained have been found to be in good agreement with reference curves available from the open literature.
\end{abstract}

Keywords: blast waves, detonation, pressure measurements, safety. 


\section{Introduction}

Although there have been important developments during the last decade, the definition of blast loads applying to a complex geometry structure is, nowadays, still a hard task when numerical simulation is used, essentially because of the different scales involved (both in space and in time). As a matter of fact, modelling the detonation of a charge and its resulting load on a structure requires modelling the charge itself, the structure and the air surrounding the charge and the structure, which rapidly leads to large size models on which parametrical studies become unaffordable. Meanwhile parametrical studies are often necessary to predict the vulnerability of structures and humans to blast.

Because full-scale testing of realistic target geometries and realistic effects of charge position are often prohibitively expansive and time consuming, as far as detonation is involved, small-scale testing is a well-proven means to assess blast loading. Indeed, many blast parameters can be scaled for charge masses ranging from milligrams to tons. The most widely used method of blast scaling is Hopkinson's “cube-root" law for scaled distance, time and impulse. This method has been used by various authors in order to assess the pressure evolution in time and space in the context of indoor detonations in a multi-chamber building [1] (Germany, 2001), to assess the vulnerability of structures and humans to blast ([2] (Canada, 2004), [3] (Japan, 2004)). Paper [1] notably shows how the blast waves may be visualized by use of particular optical techniques well adapted to small-scaled models using Nitropenta charges of $0.5 \mathrm{~g}$. Paper [2] reports how the consequences of an explosive blast in urban scenarios have been predicted by modelling, based on scaled geometries experiments and the detonation of $50 \mathrm{~g}$ C4 charges; whereas paper [3] presents an optical set-up carried out to measure pressure and to observe wave propagation when an explosion of a $10 \mathrm{mg}$ silver azide cylinder-shaped charge occurs in a modelled nuclear facility. Also, in the field of small scale experiments, the work by Brossard and co-workers [6] (France, 1980-2006) illustrates how gaseous detonation effects may also be investigated at reduced scale.

The experimental set-up described in this paper is a laboratory scale set-up, able to support detonations of solid explosives up to $64 \mathrm{~g}$ of TNT equivalent. The set-up has been designed with the objective of producing the blast pressures induced by the detonation of masses of TNT equivalent ranging from $1 \mathrm{~g}$ to $64 \mathrm{~g}$, meaning to be used as entry data for numerical assessments of the structure resistance. In the context of security, the general aim is to study the effects of blast waves in the vicinity of test installations and to test various shock wave mitigation means that could be implemented for the protection of facilities in sensitive locations. The set-up especially offers the possibility to measure the loading in terms of pressure-time curves, even for very complex situations like multiple reflections, combination and diffraction.

\section{Description of the experimental set-up}

The experimental set-up is composed of a modular table, sensors and targets and has been designed to conduct non destructive studies. Experimental campaigns 
are performed at the SNPE's Research Centre located at Le Bouchet (Vert-LePetit, France). SNPE ensures all the pyrotechnics handling aspects of the experiments, and also provided the data recording system.

\subsection{The modular table}

The small-scale configurations are tested on IRSN's blast table, which is essentially a $1.6 \times 2.4 \mathrm{~m}$ planar table. The table features an array of mounting holes that facilitate the placement of modular $40 \times 40 \times 5 \mathrm{~cm}$ wooden plates and pressure transducers.

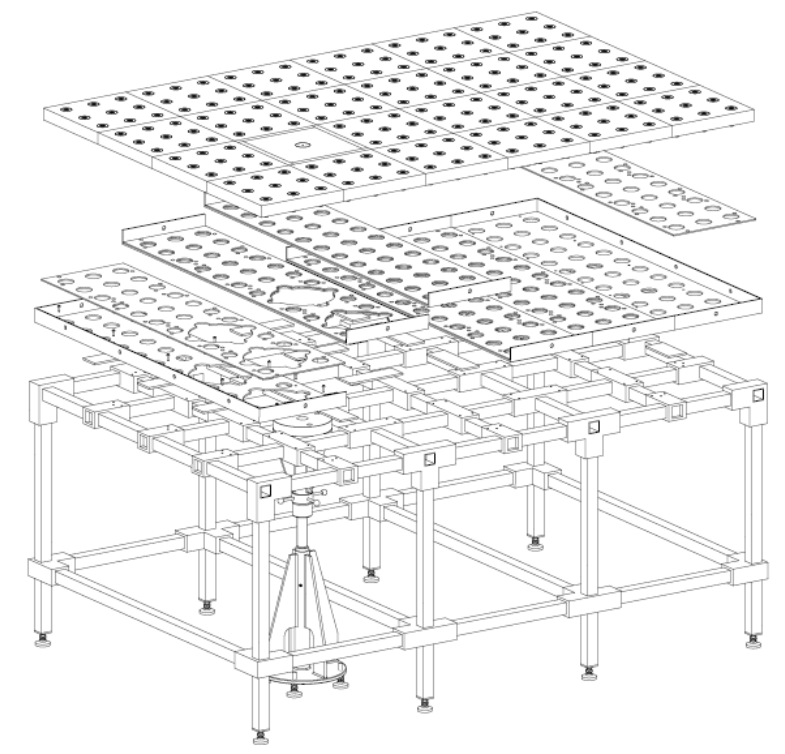

Figure 1: The modular table.

A specific steel covered and reinforced $40 \times 40 \mathrm{~cm}$ plate is supported by a specially designed stool to support the explosive charge. The modularity of the table offers the possibility to place the explosive charge at any location on the table, provided that the charge needs to be detonated at the centre of the detonation support plate. The table itself is made of a steel tubular truss structure, designed to be easily dismantled and transported. All feet are adjustable in height to permit the use of the table on any poorly planar floors (such as floor of experimental detonation bunker). The materials constituting the table are chosen so that the transmission of the shock waves by the table itself is limited.

\subsection{Gauges}

As far as the first tests campaign is concerned, eight piezoelectric pressure transducers (Kistler, 603B (0-200 bars)) and four piezoresistive pressure transducers (Endevco, 8510B (0-0.3 bars), and 8510C (0-6.9 bars)) are mounted 
on an elastic support inserted in the holes provided for this purpose. Each pressure transducer is statically calibrated with its amplifier and electric cable that connects them one to each over.

\subsection{Detonating charge}

A hemispherical charge of plastrite ${ }^{\circledR}$ is initiated from the bottom using electrical detonators. The explosive masses used for the purpose of the experiments related in the present paper are $1 \mathrm{~g}, 8 \mathrm{~g}$, and $64 \mathrm{~g}$. The aim of considering such masses is to get an easy conversion of the real distances into scaled distances, as indicated within the table 1 .

Table 1: Examples of distance conversion for the used explosive masses during the $1^{\text {st }}$ tests campaign.

\begin{tabular}{|l|c|c|c|}
\hline Explosive mass & $1 \mathrm{~g}$ & $8 \mathrm{~g}$ & $64 \mathrm{~g}$ \\
\hline $\begin{array}{l}\text { TNT hemisphere radius } \\
\left(\text { density } 1520 \mathrm{~kg} / \mathrm{m}^{3}\right)\end{array}$ & $6.8 \mathrm{~mm}$ & $13.6 \mathrm{~mm}$ & $27.2 \mathrm{~mm}$ \\
\hline $\begin{array}{l}\text { Actual distance associated with a } \\
\text { scaled distance of } 0,1 \mathrm{~m} / \mathrm{kg}^{1 / 3}\end{array}$ & $1 \mathrm{~cm}$ & $2 \mathrm{~cm}$ & $4 \mathrm{~cm}$ \\
\hline $\begin{array}{l}\text { Scaled distance associated with a real } \\
\text { distance of } 3 \mathrm{~m}\end{array}$ & $30 \mathrm{~m} / \mathrm{kg}^{1 / 3}$ & $15 \mathrm{~m} / \mathrm{kg}^{1 / 3}$ & $7,5 \mathrm{~m} / \mathrm{kg}^{1 / 3}$ \\
\hline
\end{tabular}

\subsection{Data acquisition system}

As far as this first campaign is concerned, a NICOLET Genesis (LDS Test \& Measurement) data acquisition and transient recorder system has been used for the data acquisition. Based on the concept of a mainframe with plug-in modules, the Genesis offers up to 16 channels in the portable available tower mainframe. With $200 \mathrm{kSample} / \mathrm{s}$ or $1 \mathrm{MSample} / \mathrm{s}$ digitizing rate at 16-bit resolution, it is ideally suited for high definition transient recording.

\section{Free-field tests campaign}

\subsection{Objectives}

The aim of this first free-field campaign is to validate the reduced scale experimental concept and to qualify the measurement chain.

The records of pressure vs. time history are used in order to:

- to verify the trials reproducibility and to give an estimation of the dispersion within the measures,

- to check the scaling law or Hopkinson's law,

- to determine the characteristic parameters of the blast wave - pressure, pulse, time of arrival, length of the positive phase, form factor - identified by the time evolution of the pressure, and compare the values obtained with values from abacuses available in the literature. 
The references associated with the last two points are formulas of abacuses from the books by Kinney and Graham [8] and by Baker et al. [9].

\subsection{Geometrical definition of the campaign}

\subsubsection{Selection of table location}

The modular table is placed at the centre of a closed $7 \times 8 \mathrm{~m}$ bunker to avoid the perturbation from reflection from the walls.

\subsubsection{Selection of gauges and charge locations}

A series of three trials has been conducted for each mass of explosive $(1 \mathrm{~g}, 8 \mathrm{~g}$ and $64 \mathrm{~g}$ ). For each of these trials, a set of eight pressure transducers is placed on the table. Three ranges of a set of positions for pressure transducers are planned: a near-field area (labelled (A)), an intermediate-field area (labelled (B)), and a far-field area (labelled (C)). For each range, pressure transducers are placed with reference to the explosive charge at distances set among a geometric progression: this is designed to obtain a homogeneous range of sampling distances for an exploitation of the results on a logarithmic scale.

Finally, each configuration trial is performed twice, in order to assess the dispersion in the reproducibility of measurements.

The total number of trials during this first tests campaign is 18 as indicated in table 2 .

Table 2: Trials denomination.

\begin{tabular}{|c|c|c|c|}
\cline { 2 - 4 } \multicolumn{1}{c|}{} & \multicolumn{3}{c|}{ Trial denomination } \\
\hline Explosive mass & Area (A) & Area (B) & Area (C) \\
\hline $1 \mathrm{~g}$ & $1 \mathrm{a} / 1 \mathrm{~b}$ & $4 \mathrm{a} / 4 \mathrm{~b}$ & $7 \mathrm{a} / 7 \mathrm{~b}$ \\
\hline $8 \mathrm{~g}$ & $2 \mathrm{a} / 2 \mathrm{~b}$ & $5 \mathrm{a} / 5 \mathrm{~b}$ & $8 \mathrm{a} / 8 \mathrm{~b}$ \\
\hline $64 \mathrm{~g}$ & $3 \mathrm{a} / 3 \mathrm{~b}$ & $6 \mathrm{a} / 6 \mathrm{~b}$ & $9 \mathrm{a} / 9 \mathrm{~b}$ \\
\hline
\end{tabular}

Between two adjacent areas, transition points of measurements are set: thus for each zone, the farthest transducer is included in the next area as the nearest transducer. As a result of their limited range of use dedicated to low pressure measurements, Endevco pressure transducers are preferentially used in far-field areas. They are arranged in addition to the Kistler 603B to make statements at the same distance, at low pressure. This allows comparing the behaviour of Kistler and Endevco pressure transducers in the range of use.

\subsection{Free-field results}

\subsubsection{Results}

The verification focused on the positive part of the pressure-time history signal, i.e.:

- $\quad$ the time of arrival of the blast wave (ta),

- the peak overpressure maximum $\left(\mathrm{P}_{\max }\right)$,

- $\quad$ the impulse $\left(\mathrm{I}^{+}\right)$and the duration $(\mathrm{td})$ of the positive phase,

- $\quad$ and their non dimensional equivalents. 


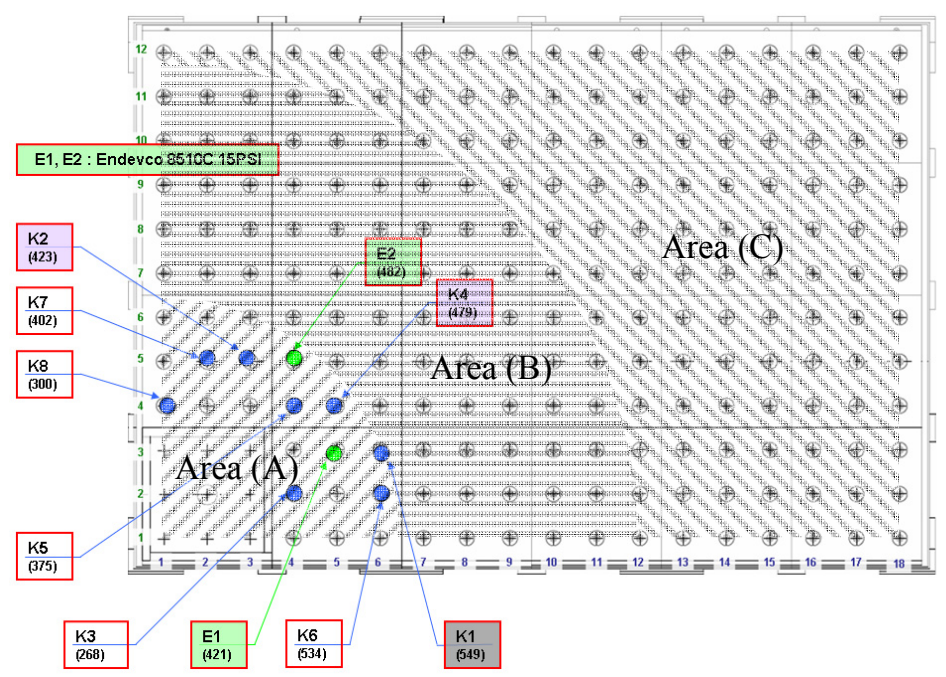

Figure 2: Positioning of pressure transducers on area: (A) definition of areas (B) and $(\mathrm{C})$.

Several formulas have been empirically established to express the maximum overpressure for an observer in the field of a strong detonation of explosives. Such a formula, extracted from the reference [8], is given by equation (1) below and is also represented by a solid line on figure 2 .

$$
\frac{P_{\max }}{P_{0}}=\frac{808\left[1+\left(\frac{z}{4.5}\right)^{2}\right]}{\sqrt{1+\left(\frac{z}{0.048}\right)^{2}} \sqrt{1+\left(\frac{z}{0.32}\right)^{2}} \sqrt{1+\left(\frac{z}{1.35}\right)^{2}}}
$$

where $\mathrm{m}$ is the mass of the sphere, $\mathrm{z}$ is the reduced distance defined as $\mathrm{r} / \mathrm{m}^{1 / 3}$ and $r$ is the distance between the centre of the hemisphere and the observer.

The maximum overpressures obtained by the detonation of a half-sphere on the table are equivalent to the overpressures obtained by the detonation of a sphere of same radius in the open air. The mass considered here is equal to twice the mass of the hemisphere used in the tests, weighted by the ratio of TNT equivalent plastrite ${ }^{\circledR}$ for overpressure. This coefficient was determined during a preliminary test phase whose objective was to determine the TNT equivalent of plastrite ${ }^{\circledR}$. In the end we get $\mathrm{m}=1.27 \times 2 \mathrm{x} \mathrm{m}_{\text {tests }}$.

The relative error of measurement is determined by the difference between the measured pressure and the pressure assessed using the formula eqn. (1), referred to be the theoretical value, as follows (see table 3): 


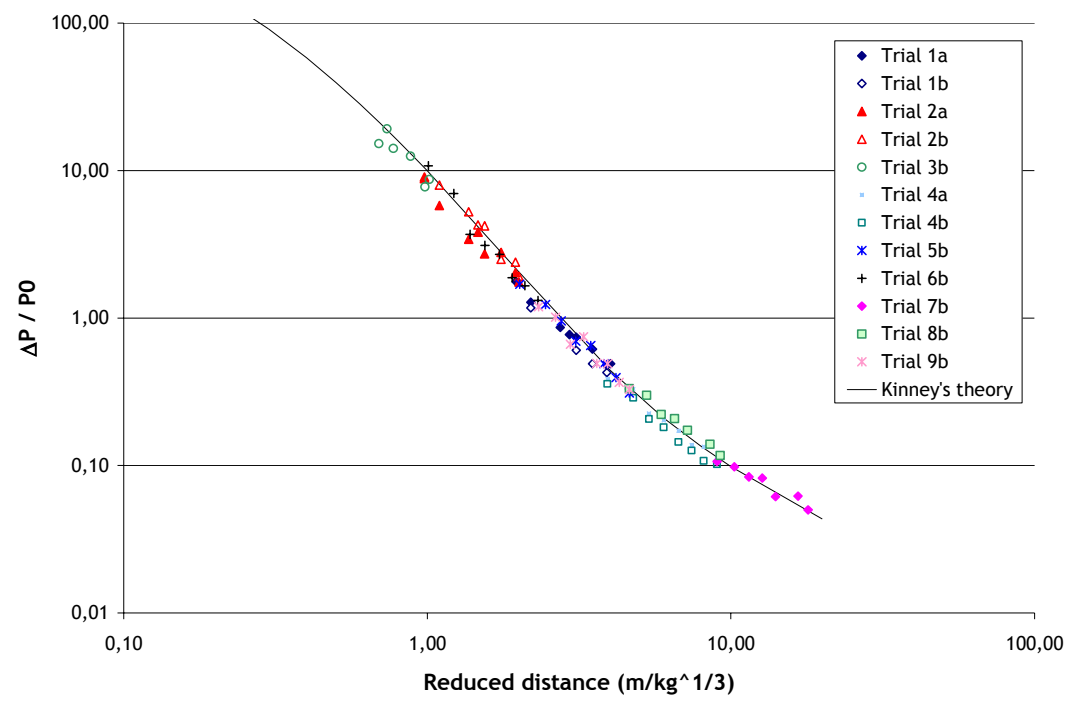

Figure 3: Overpressure vs. scaled distance.

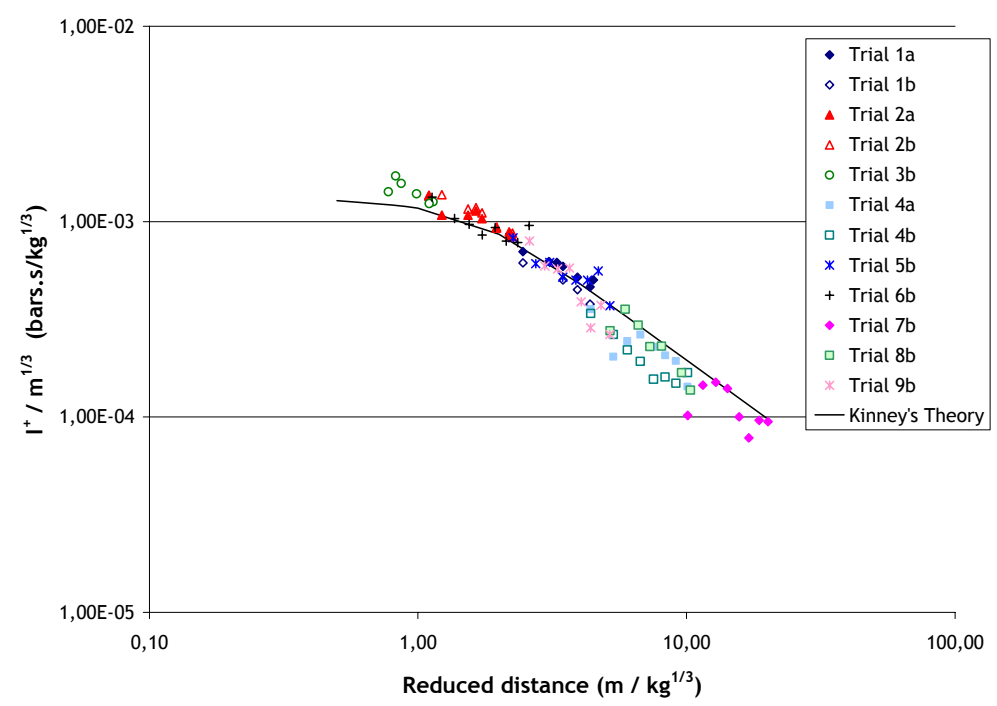

Figure 4: Positive phase impulse vs. scaled distance.

error $=[$ Measured pressure - pressure calculated by eqn. (1) $]$ / Pressure calculated by eqn. (1)

The results concerning the impulse of the pressure-time history are treated similarly, using a TNT equivalent plastrite ${ }^{\circledR}$ for impulse of 0.90 (see figure 4). 
As far as each characteristic of the pressure-time history signal is concerned, histograms of relative errors were plotted: means and standard deviations of the relative errors are summed up in table 3 which shows a good agreement between the measured performed with the small-scale experiment set-up and theory. It has to be noticed that the standard deviation remains relatively small for that kind of experiments. In addition, bias is almost zero for overpressure and times, whereas it reaches around $10 \%$ for the impulse measurements. This parameter is also widely dispersed from an experimental standpoint.

Table 3: $\quad$ Means and standard deviation of relative errors.

\begin{tabular}{|l|c|c|c|c|}
\hline Measurand & $\Delta \mathrm{P}_{\max } / \mathrm{P}_{0}$ & $\mathrm{ta} / \mathrm{m}^{1 / 3}$ & $\mathrm{td} / \mathrm{m}^{1 / 3}$ & $\mathrm{I}^{+} / \mathrm{m}^{1 / 3}$ \\
\hline Mean & $-5 \%$ & $-0.8 \%$ & $9.5 \%$ & $-10 \%$ \\
\hline $\begin{array}{l}\text { Standard } \\
\text { deviation }\end{array}$ & $15 \%$ & $-9 \%$ & $26 \%$ & $20 \%$ \\
\hline
\end{tabular}

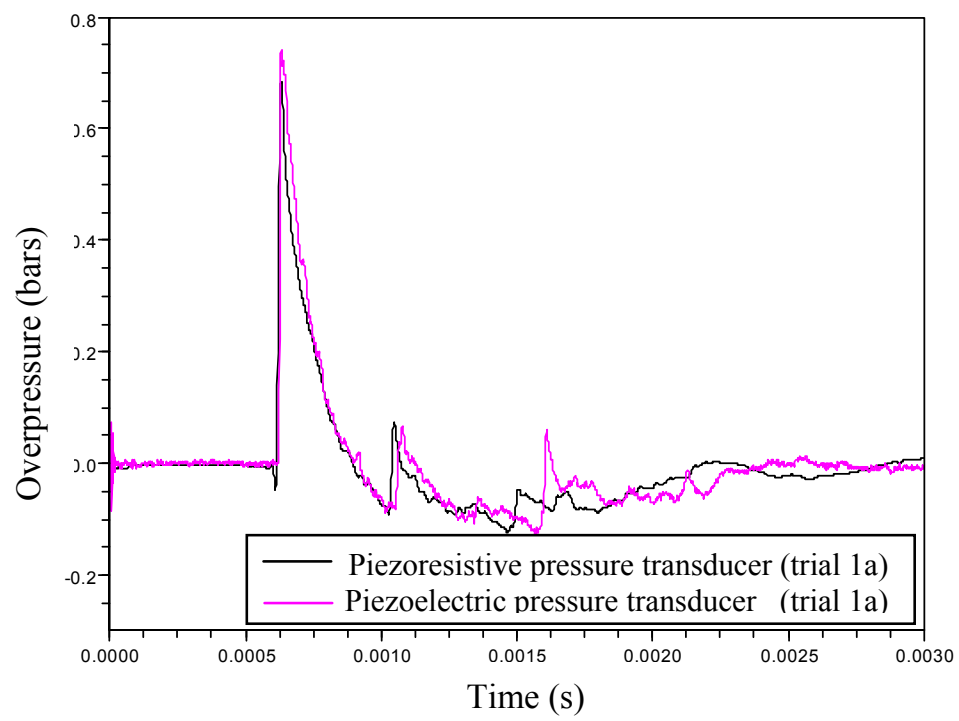

Figure 5: Recorded piezoelectric and piezoresistive pressure transducers comparison.

\subsubsection{Comparison of pressure transducer technologies}

In intermediate-field area as well as in far-field area, as illustrated with figure 5, piezoresistive and piezoelectric pressure transducers give the same information for the overpressure, the time of arrival, the impulse and the duration of the positive phase. On the one hand, it may appear that piezoresistive pressure transducers present the drawback of an oscillatory behaviour that requires the use of numerical filtering. On the other hand, in near-field area, especially with the higher explosive charge we tested (64 g), every Kistler (piezoelectric) pressure transducer reported a continuous depression after the passage of the wave, during 
the negative phase of the signal, which makes the signals recorded impossible to be processed when the characteristics of the negative phase are investigated. This effect has already been observed with test gaseous bubbles detonation in nearfield measurements [7].

As can be read in open literature concerning piezoresistive and piezoelectric pressure transducers, the two technologies are well suited for detonic experiments. Nevertheless, piezoelectric materials exhibit pyroelectric properties which could greatly influence the quality of the measure. It may therefore be possible that piezoelectric pressure transducers would be, for a big explosive charge and in near-field, in a measure range where the pyroelectric property would be highlighted: it would be the case when transducers where placed within the space for the expansion of the fireball. Empirical formula [10] can be used to evaluate the radius of the fireball generated within fuel detonations, as a function of the mass of hydrocarbons. Nevertheless, these formulas do not allow determining the radius of the fireball associated with solid explosive detonations.

\section{Conclusion}

In order to conduct security studies in which the effects of blast waves in the vicinity of industrial sensitive installations need to be investigated, IRSN has developed an experimental set-up composed of a modular table and pressure transducers. The experimental set-up is a support for non destructive studies and dedicated to testing various shock wave mitigation means that could be implemented for the protection of facilities in sensitive locations. The first campaign performed in the end of 2006 allowed to qualify the measurement chain and to validate the concept of small-scale experiments. This validation was conducted through a free-field campaign of measurements, and the results were compared with the data currently available in open literature. As a matter of fact, overpressure maxima, arrival time of the shock wave and impulse of pressure time histories are presented as non dimensional characteristics of the pressure time history and have been found in good agreement with reference curves available from the open literature. The set-up now offers the possibility to measure the loading in terms of pressure-time curves and is now ready for more complex situations, such as multiple reflections, combination, diffraction, or parametrical studies upon the shape of the explosive (cylinder, hemisphere, cube, ...) under miscellaneous detonation configurations (at altitude, multiple detonation).

\section{References}

[1] Reichenbach H., Neuwald P., Indoor detonations - Visualization and pressure measurements in small-scale models, Proceedings of SPIE - The International Society for Optical Engineering 4183, pp. 92-104, 2001.

[2] Ripley R.C., von Rosen B., Ritzel D.V., Whitehouse D.R., Small-Scale Modeling of Explosive Blasts in Urban Scenarios, 21st International Symposium on Ballistics, April 19-23, 2004, Adelaide, Australia. 
[3] Miura A., Matsuo A., Mizukaki T., Shiraishi T., Utsunomiya G., Takayama K., Nojiri I., Reflection and diffraction Phenomena of Blast Wave Propagation in Nuclear Fuel Cycle Facility, JSME International Journal, Series B: Fluids and Thermal Engineering 47 (2), pp. 287-292, 2004.

[4] Mizukaki T., Takayama K., Experimental simulation of large-scale explosion using a micro-charge explosion (II) - Numerical study on shock waves propagation starting from detonation wave propagation in explosive, Science and Technology of Energetic Materials 66 (1), pp. 248254, 2005.

[5] Mizukaki T., Miura A., Takayama K., Experimental simulation of largescale explosion using a micro-charge explosion (I) - Behaviour of shock waves in a complicated closed-space, Science and Technology of Energetic Materials 65 (5), pp. 180-188, 2004.

[6] Brossard J., Bailly P., Desrosier C., Renard J., Overpressure imposed by a blast wave, Progress in Astronautics and Aeronautics, Vol. 114, pp. 329400, 1988.

[7] Trélat S., Sochet I., Autrusson B., Loiseau O., Cheval K., Strong explosion near a parallelepipedic structure, Shock Waves 16 (4-5), pp. 349-357, 2007.

[8] Kinney, Graham, Explosive Shocks in Air, Springer Verlag (1962)

[9] Baker et al., Explosion Hazards and Evaluations, Elsevier (1983).

[10] Dorofeev S.B., Fireballs from deflagration and detonation of heterogeneous fuel-rich clouds, Fire Safety Journal, 25, pp. 323-336, 1995. 